\title{
Density-functional theory studies of acetone and propanal hydrogenation on $\operatorname{Pt}(111)$
}

\author{
R. Alcalá, J. Greeley, M. Mavrikakis, and J. A. Dumesic ${ }^{a)}$ \\ Department of Chemical Engineering, University of Wisconsin-Madison, Madison, Wisconsin 53706
}

(Received 6 December 2001; accepted 27 February 2002)

\begin{abstract}
Self-consistent periodic slab calculations based on gradient-corrected density-functional theory (DFT-GGA) were conducted to probe the potential-energy diagram for the hydrogenation of propanal and acetone on $\mathrm{Pt}(111)$. Calculations for molecularly adsorbed species indicate that acetone and propanal are both weakly bound to the surface through oxygen (i.e., energy changes of adsorption near $-20 \mathrm{~kJ} / \mathrm{mol}$ ). The activation energy barriers are calculated to be $\sim 60$ and $40 \mathrm{~kJ} / \mathrm{mol}$ for the addition of an adsorbed hydrogen atom to adsorbed acetone and propanal, leading to adsorbed isopropoxy and $n$-propoxy species, respectively. The subsequent hydrogenation steps to form adsorbed alcohol species have activation barriers near $15 \mathrm{~kJ} / \mathrm{mol}$. These results would suggest that the rate of propanal hydrogenation over Pt should be faster compared to acetone hydrogenation, in contrast to the behavior observed experimentally [G.M.R. van Druten and V. Ponec, Applied Catalysis A: General 191, 153 (2000)]. The origin for the experimentally observed slower rate of propanal hydrogenation over Pt appears to be related to the formation of strongly adsorbed spectator species formed by removal of the $\alpha-\mathrm{H}$ atom from adsorbed propanal. The calculated energy change for cleavage of this $\mathrm{C}-\mathrm{H}$ bond, leading to adsorbed propionyl and adsorbed hydrogen atom, is exothermic by 76 kJ/mol. (C) 2002 American Institute of Physics. [DOI: 10.1063/1.1471247]
\end{abstract}

\section{INTRODUCTION}

Reactions of oxygenated hydrocarbons on transition metal surfaces are important in many areas of heterogeneous catalysis, including (i) selective oxidations of hydrocarbons to oxygenated chemicals, (ii) reductions of carboxylic acid groups, and (iii) selective hydrogenations of $\alpha, \beta$-unsaturated carbonyls to produce unsaturated alcohols. ${ }^{1}$ With respect to the latter of these applications, the selectivity for the formation of the unsaturated alcohol compared to the saturated aldehyde or ketone is controlled by the relative rates of reduction of the $\mathrm{C}=\mathrm{O}$ group compared to reduction of the $\mathrm{C}=\mathrm{C}$ bond. For example, monometallic platinum catalysts generally favor hydrogenation of the $\mathrm{C}=\mathrm{C}$ double bond to yield saturated carbonyl species, whereas addition of a second metal (such as $\mathrm{Fe}, \mathrm{Ni}$, and $\mathrm{Sn}$ ) to Pt catalysts generally improves the selectivity for the formation of the unsaturated alcohol. $^{2-7}$ To our knowledge, density-function theory (DFT) calculations have not been carried out to probe the factors controlling the rate of hydrogenation of carbonyl functional groups in hydrocarbons. Accordingly, the present paper deals with the application of DFT calculations to study the hydrogenation over $\mathrm{Pt}(111)$ of the carbonyl group in aldehydes and ketones, using propanal and acetone as probe molecules.

Results from recent reaction kinetics studies of the hydrogenation of the carbonyl group in propanal and acetone on silica supported Pt at 373 and $423 \mathrm{~K}$ indicate that the rate of propanal hydrogenation is significantly slower than the hydrogenation of acetone. ${ }^{8}$ In a subsequent paper, ${ }^{9}$ the investigators propose a mechanism in which hydrogenation of the

\footnotetext{
a) Author to whom correspondence should be addresed. Electronic mail: dumesic@engr.wisc.edu
}

carbonyl group begins with formation of a $\mathrm{C}-\mathrm{H}$ bond, yielding an alkoxy intermediate followed by addition of a second $\mathrm{H}$ atom to the alkoxy intermediate to form an adsorbed alcohol. Experimental studies of the rates of hydrogenation of hydrocarbons containing carbonyl groups over alumina supported $\mathrm{Pt}$ at $\sim 400 \mathrm{~K}$ have also shown that the rate of propanal hydrogenation is slower than the rate of acetone hydrogenation. ${ }^{10}$ These authors suggest that hydrogenation proceeds through a mechanism involving a hydroxyalkyl species, i.e., addition of the first hydrogen occurs at the $\mathrm{O}$ atom. The DFT calculations of the present study were conducted with the aim of addressing the higher rate of hydrogenation of acetone compared to propanal over Pt.

Various experimental studies under ultrahigh vacuum conditions have been conducted to study the adsorption of hydrocarbons containing carbonyl groups on various Pt surfaces. For example, electron energy loss spectroscopy, temperature programmed desorption, and Auger electron spectroscopy have been used to study acetone adsorption, desorption, and decomposition on a Pt foil. ${ }^{11}$ At temperatures below $200 \mathrm{~K}$, acetone adsorbs in the perpendicular mode. At higher temperatures, acetone adsorbs in the parallel mode and decomposition competes with desorption. The appearance of the parallel adsorption mode was attributed to adsorption of acetone on defect sites.

Temperature-programmed desorption (TPD) and mass spectroscopy was used to study the adsorption of methanol and ethanol on $\mathrm{Pt}(111){ }^{12}$ Estimated energy changes for desorption of molecularly adsorbed methanol and ethanol were $\sim 50 \mathrm{~kJ} / \mathrm{mol}$. For comparison, the energy change for methanol adsorption on $\mathrm{Pt}(111)$ has recently been calculated to be -32 kJ/mol, using periodic self-consistent DFT calcula- 
tions. ${ }^{13}$ Gibson et al. have shown that molecular desorption of methanol competes with surface decomposition reactions on defect sites at temperatures above $145 \mathrm{~K}^{14}$

Ihm et al. have recently reported the formation of oxametallacycles from the dehydrogenation of alkoxy species on $\mathrm{Pt}(111) .{ }^{15}$ These investigators suggested that oxametallacycle species might lose hydrogen atoms and decompose irrevers-

(a)

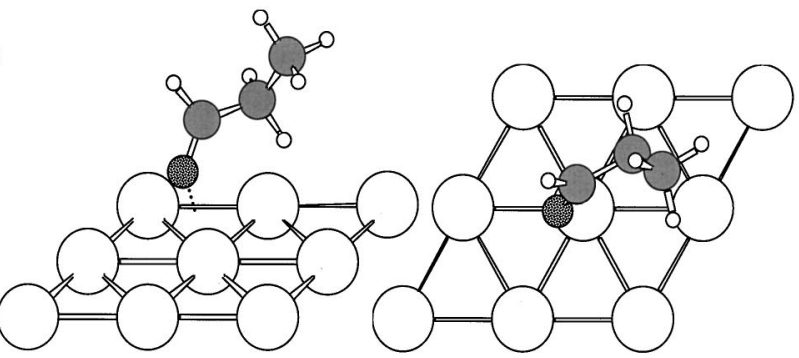

(b)

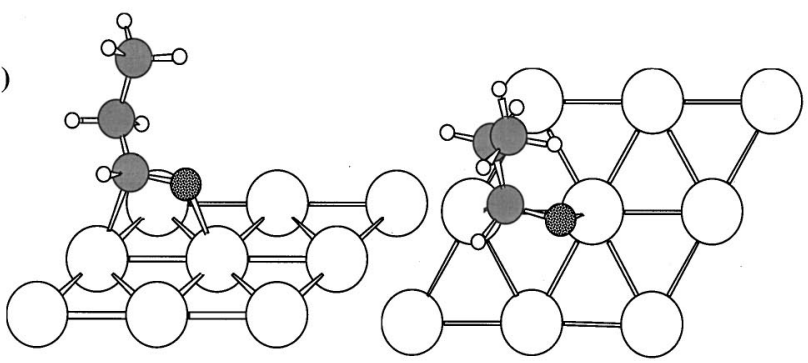

(c)

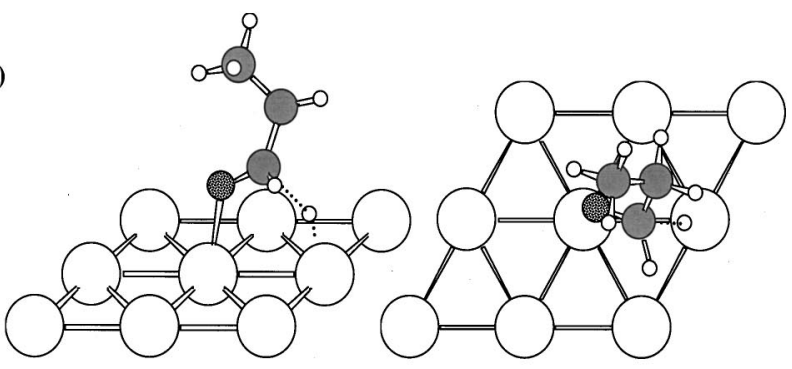

(d)

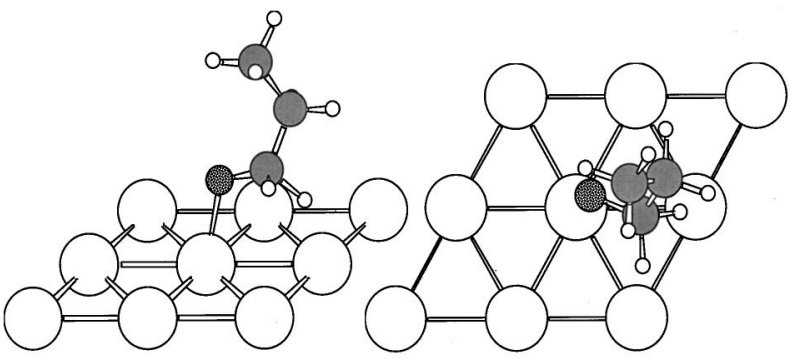

ibly at temperatures higher than $300 \mathrm{~K}$, forming $\mathrm{CO}, \mathrm{H}$, and C. Oxametallacycle species have been recently identified as common surface reaction intermediates in oxygenate surface reactions on transition metal surfaces. ${ }^{1,16,17}$ Therefore, we have addressed in the present paper the possibility of forming oxametallacycle species during the hydrogenation of propanal and acetone on $\operatorname{Pt}(111)$. (e)

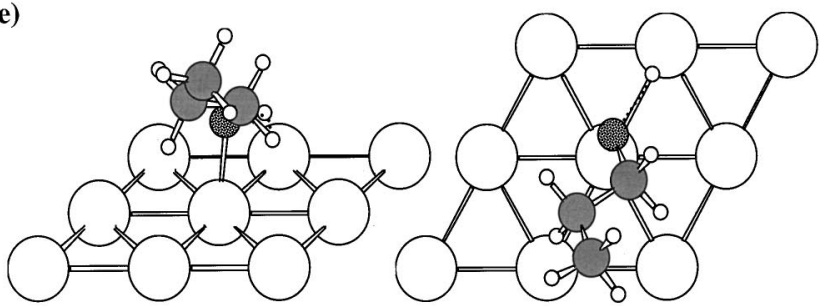

(f)

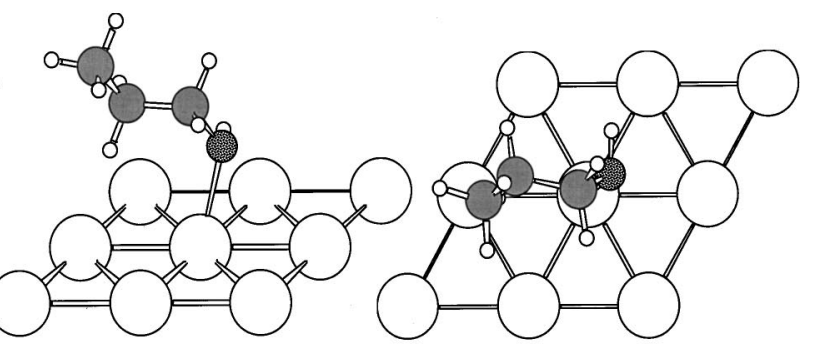

(g)

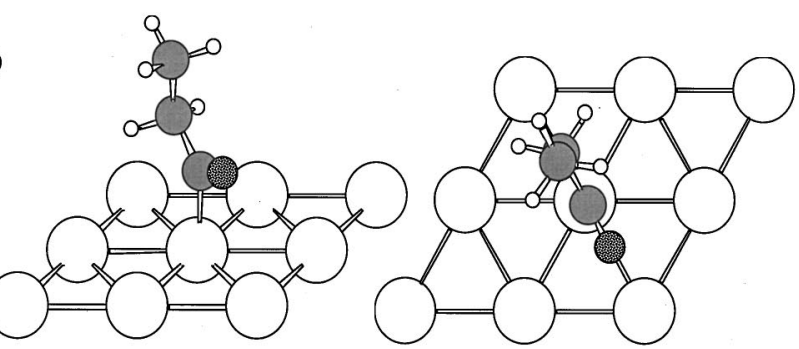

(h)

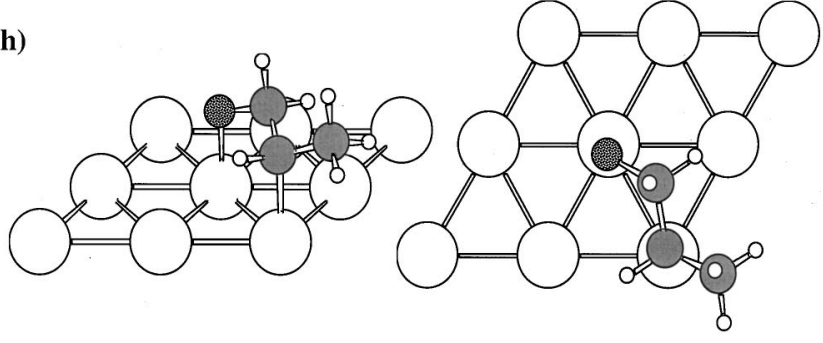

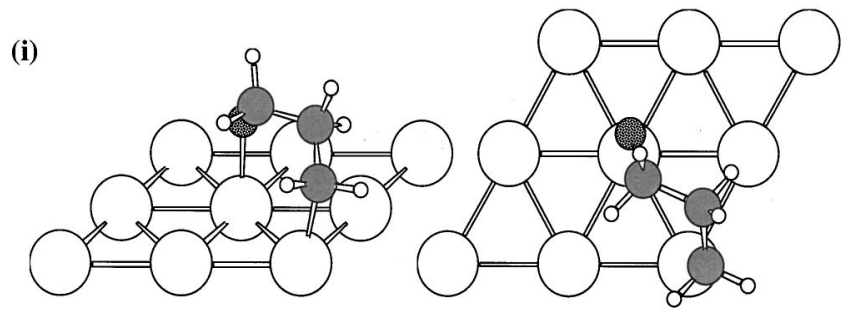

FIG. 1. (a)-(i). Side and top views of adsorption modes of propanal hydrogenation and dehydrogenation intermediates on Pt(111) (only top layer is shown). The corresponding surface species for acetone hydrogenation are obtained by replacing the ethyl group and the $\alpha-\mathrm{H}$ atom with methyl groups [(a) $-(\mathrm{f})$ only]. Large white circle $=\mathrm{Pt}$ atom; medium gray circle $=\mathrm{C}$ atom; medium checkered circle $=\mathrm{O}$ atom; and small white circle $=\mathrm{H}$ atom. (a) carbonyl molecular adsorption $\left(\eta_{1} \mu_{1}\right)$; (b) carbonyl molecular adsorption $\left(\eta_{2} \mu_{2}\right)$; (c) carbonyl-alkoxy transition state $\left(\mathrm{TS}_{1}\right)$; (d) alkoxy $\left(\eta_{1} \mu_{1}\right)$; (e) alkoxy-alcohol transition state $\left(\mathrm{TS}_{2}\right)$; (f) alcohol $\left(\eta_{1} \mu_{1}\right)$; (g) propionyl $\left(\eta_{1} \mu_{1}\right)$; (h) oxametallacycle, $\mathrm{OCH}_{2} \mathrm{CHCH}_{3}\left(\eta_{2} \mu_{2}\right)$; (i) oxametallacycle, $\mathrm{OCH}_{2} \mathrm{CH}_{2} \mathrm{CH}_{2}\left(\eta_{2} \mu_{2}\right)$. 
TABLE I. Bond lengths $(\AA)$ from DFT calculations for propanal hydrogenation on $\operatorname{Pt}(111)(\theta=1 / 9 \mathrm{ML})$. Values in bold correspond to bond being formed.

\begin{tabular}{|c|c|c|c|c|c|c|c|c|c|c|c|}
\hline Bond & $\begin{array}{l}\text { Propanal } \\
\text { (gas) }\end{array}$ & $\begin{array}{c}\text { Propanal } \\
\left(\eta_{1} \mu_{1}\right)\end{array}$ & $\begin{array}{c}\text { Propanal } \\
\left(\eta_{2} \mu_{2}\right)\end{array}$ & $\mathrm{TS}_{1}$ & $\begin{array}{l}\text { n-propoxy } \\
\quad\left(\eta_{1} \mu_{1}\right)\end{array}$ & $\mathrm{TS}_{2}$ & $\begin{array}{c}\text { Propanol } \\
\left(\eta_{1} \mu_{1}\right)\end{array}$ & $\begin{array}{l}\text { Propanol } \\
\text { (gas) }\end{array}$ & $\begin{array}{l}\text { Propionyl } \\
\left(\eta_{1} \mu_{1}\right)\end{array}$ & $\begin{array}{c}\text { Cycle } \\
\mathrm{OCH}_{2} \mathrm{CHCH}_{3}\end{array}$ & $\begin{array}{c}\text { Cycle } \\
\mathrm{OCH}_{2} \mathrm{CH}_{2} \mathrm{CH}_{2}\end{array}$ \\
\hline $\mathrm{O}-\mathrm{Pt}$ & & 2.39 & 2.13 & 2.17 & 2.11 & 2.08 & 2.41 & & & 2.03 & 2.03 \\
\hline $\mathrm{C}-\mathrm{Pt}$ & & & 2.24 & & & & & & 2.06 & 2.13 & 2.12 \\
\hline $\mathrm{H}-\mathrm{Pt}$ & & & & 1.70 & 1.80 & 1.62 & & & & & \\
\hline $\mathrm{C}-\mathrm{O}$ & 1.22 & 1.24 & 1.34 & 1.31 & 1.35 & 1.42 & 1.44 & 1.43 & 1.22 & 1.39 & 1.40 \\
\hline $\mathrm{C}-\mathrm{C}$ & 1.52 & $1.48,1.53$ & 1.52 & 1.52 & 1.52 & 1.52 & 1.52 & 1.52 & 1.52 & 1.52 & 1.52 \\
\hline $\mathrm{C}-\mathrm{H}$ & $1.10,1.12$ & $1.10,1.12$ & $1.10,1.13$ & $1.10, \mathbf{1 . 4 0}$ & $1.10,1.24$ & 1.10 & 1.10 & 1.10 & 1.10 & $1.10,1.13$ & 1.10 \\
\hline $\mathrm{O}-\mathrm{H}$ & & & & & & 1.73 & 0.99 & 0.98 & & & \\
\hline
\end{tabular}

As noted above, results of DFT calculations have not been reported for the hydrogenation of carbonyl compounds. However, extended Hückel calculations using large Pt clusters have been conducted to probe the adsorption on $\mathrm{Pt}(111)$ facets of hydrocarbon species containing carbonyl groups. ${ }^{18,19}$ The calculated energy changes of adsorption for formaldehyde, acetaldehyde, and acetone were near $-40 \mathrm{~kJ} /$ mol for the perpendicular $\left(\eta_{1} \mu_{1}\right)$ adsorption modes of these molecules. In contrast, the energy changes for the parallel $\left(\eta_{2} \mu_{2}\right)$ modes of adsorption for formaldehyde, acetaldehyde, and acetone were calculated to be $-96,-60$, and -21 $\mathrm{kJ} / \mathrm{mol}$, respectively. Accordingly, acetone was the only molecule that favored the perpendicular mode of adsorption. We will use DFT calculations in the present study to address this trend in the relative binding energies on $\mathrm{Pt}(111)$ of formaldehyde, acetaldehyde, propanal, and acetone.

\section{METHODS}

Self-consistent periodic slab calculations based on gradient-corrected density functional theory (DFT-GGA) were conducted for two-layer $\operatorname{Pt}(111)$ slabs. The $(3 \times 3 \times 2)$ unit cell, containing a total of 18 metal atoms, was repeated periodically, with four equivalent layers of vacuum between any two successive metal slabs. The total energy calculations were performed using DACAPO. ${ }^{20}$ Ionic cores are described by ultrasoft pseudopotentials ${ }^{21}$ and the Kohn-Sham oneelectron valence states are expanded in a basis of plane waves with kinetic energies below $25 \mathrm{Ry}$. The surface Brillouin zone is sampled at six special $k$-points. Convergence with respect to the number of metal layers included in the slab and $k$-points has been confirmed using 18 special $k$-points. The calculated energy change for alcohol adsorption on three-layer slabs differed by less than $10 \mathrm{~kJ} / \mathrm{mol} \mathrm{com-}$ pared to two-layer slabs. The exchange-correlation energy and potential are described by the Perdew-Wang 1991
(PW91) generalized gradient approximation (PW91). ${ }^{22,23}$ The self-consistent density is determined by iterative diagonalization of the Kohn-Sham Hamiltonian, Fermipopulation of the Kohn-Sham states $\left(k_{B} T=0.1 \mathrm{eV}\right)$ and $\mathrm{Pu}$ lay mixing of the resulting electronic density. ${ }^{24}$ All of the reported binding energies are calculated using the PW91 functional and these energies have been extrapolated to $k_{B} T=0 \mathrm{eV}$.

Adsorption occurs on one side of the slab. The metal atoms were fixed in their bulk-terminated positions and all adsorbate atoms were allowed to relax. The lattice constant used in the calculations was $4.00 \AA,^{25}$ compared to the experimental bulk lattice constant of $3.93 \AA \AA^{26}$ Gas-phase calculations are carried out on a $15.0 \AA$ unit cell. Transition states are estimated using constrained optimizations, where the bond length representing the reaction coordinate is constrained and all other degrees of freedom are optimized. The transition state of the hydrogenation reactions is characterized by the configuration with the highest energy along the reaction coordinate and a transition from repulsive to attractive forces along the constrained bond. ${ }^{25,27,28}$ This procedure for determining the transition state of relatively large adsorbates has proven to yield energy barriers of reasonable accuracy, compared to more rigorous methods, such as the nudged elastic band (NEB) method. ${ }^{13,29-31}$

\section{RESULTS}

The results of the DFT calculations in the present work will be compared to experimental reaction kinetics results reported by van Druten et al. for the hydrogenation of propanal and acetone over Pt. ${ }^{8,9}$ Since these authors suggested that these hydrogenation reactions take place through adsorbed alkoxy species, we have investigated this pathway in the present work.

Adsorption geometries of various surface species on the $\operatorname{Pt}(111)(\theta=1 / 9 \mathrm{ML})$ as determined by our calculations are

TABLE II. Bond lengths $(\AA)$ from DFT calculations for acetone hydrogenation on $\operatorname{Pt}(111)(\theta=1 / 9 \mathrm{ML})$. Values in bold correspond to bond being formed.

\begin{tabular}{|c|c|c|c|c|c|c|c|c|}
\hline Bond & $\begin{array}{l}\text { Acetone } \\
\text { (gas) }\end{array}$ & $\begin{array}{l}\text { Acetone } \\
\left(\eta_{1} \mu_{1}\right)\end{array}$ & $\mathrm{TS}_{1}$ & $\begin{array}{l}\text { Isopropoxy } \\
\quad\left(\eta_{1} \mu_{1}\right)\end{array}$ & $\mathrm{TS}_{2}$ & $\begin{array}{l}\text { Isopropanol } \\
\quad\left(\eta_{1} \mu_{1}\right)\end{array}$ & $\begin{array}{l}\text { Isopropanol } \\
\text { (gas) }\end{array}$ & $\begin{array}{c}\text { Cycle } \\
\mathrm{OCHCH}_{3} \mathrm{CH}_{2}\end{array}$ \\
\hline $\mathrm{O}-\mathrm{Pt}$ & & 2.43 & 2.18 & 2.14 & 2.10 & 2.52 & & 2.02 \\
\hline $\mathrm{C}-\mathrm{Pt}$ & & & & & & & & 2.10 \\
\hline $\mathrm{H}-\mathrm{Pt}$ & & & 1.72 & 1.84 & 1.64 & & & \\
\hline $\mathrm{C}-\mathrm{O}$ & 1.23 & 1.24 & 1.32 & 1.36 & 1.44 & 1.46 & 1.44 & 1.40 \\
\hline $\mathrm{C}-\mathrm{C}$ & 1.50 & 1.50 & 1.51 & 1.52 & 1.52 & 1.52 & 1.52 & 1.52 \\
\hline $\mathrm{C}-\mathrm{H}$ & 1.10 & 1.10 & $1.10, \mathbf{1 . 4 0}$ & $1.10,1.24$ & 1.10 & 1.10 & 1.10 & $1.10,1.12$ \\
\hline $\mathrm{O}-\mathrm{H}$ & & & & & 1.68 & 1.00 & 0.98 & \\
\hline
\end{tabular}


TABLE III. Results from DFT calculations for changes in total energies $(\mathrm{kJ} / \mathrm{mol})$ for carbonyl adsorption and hydrogenation on $\operatorname{Pt}(111)(\theta=1 / 9 \mathrm{ML})$.

\begin{tabular}{|c|c|c|c|c|}
\hline Reaction $^{\mathrm{a}}$ & $\begin{array}{l}\text { Acetone } \\
\text { i-c3 }\end{array}$ & $\begin{array}{c}\text { Propanal } \\
n-\mathrm{c} 3\end{array}$ & $\begin{array}{l}\text { Acetaldehyde } \\
\text { c2 }\end{array}$ & $\begin{array}{c}\text { Formaldehyde } \\
\text { c1 }\end{array}$ \\
\hline $\begin{array}{l}\mathrm{H}_{2}+2 * \Leftrightarrow 2 \mathrm{H}^{*} \\
\text { Carbonyl Adsorption }\end{array}$ & -84 & -84 & -84 & -84 \\
\hline$>\mathrm{C}=\mathrm{O}+* \Leftrightarrow \eta_{1} \mu_{1}^{*}$ & -19 & -18 & -18 & -14 \\
\hline$>\mathrm{C}=\mathrm{O}+* \Leftrightarrow \eta_{2} \mu_{2} *$ & & -7 & -4 & -38 \\
\hline$>\mathrm{C}=\mathrm{O}+\mathrm{H}_{2}+3 * \Leftrightarrow \eta_{1} \mu_{1} *+2 \mathrm{H}^{*}$ & -103 & -102 & -102 & -98 \\
\hline $\begin{array}{l}>\mathrm{C}=\mathrm{O}+\mathrm{H}_{2}+3 * \Leftrightarrow \eta_{2} \mu_{2} *+2 \mathrm{H}^{*} \\
\text { Alkoxy }\end{array}$ & -65 & -91 & -88 & -122 \\
\hline$>\mathrm{C}=\mathrm{O}+\mathrm{H}_{2}+2^{*} \Leftrightarrow \mathrm{TS} 1^{*}+\mathrm{H}^{*}$ & -42 & -62 & & \\
\hline $\begin{array}{l}>\mathrm{C}=\mathrm{O}+\mathrm{H}_{2}+2^{*} \Leftrightarrow \eta_{1} \mu_{1} *+\mathrm{H}^{*} \\
\text { Adsorbed Alcohol }\end{array}$ & -45 & -67 & & \\
\hline $\begin{array}{l}>\mathrm{C}=\mathrm{O}+\mathrm{H}_{2}+* \Leftrightarrow \mathrm{TS} 2^{*} \\
>\mathrm{C}=\mathrm{O}+\mathrm{H}_{2}+* \Leftrightarrow \eta_{1} \mu_{1}^{*} \\
\text { Overall Reaction }\end{array}$ & $\begin{array}{l}-27 \\
-98\end{array}$ & $\begin{array}{l}-48 \\
-125\end{array}$ & & \\
\hline $\begin{array}{l}>\mathrm{C}=\mathrm{O}+\mathrm{H}_{2} \Leftrightarrow>\mathrm{CH}-\mathrm{OH} \\
\text { Carbonyl Dehydrogenation }\end{array}$ & -80 & -100 & -97 & -128 \\
\hline$>\mathrm{C}=\mathrm{O}+\mathrm{H}_{2}+3^{*} \Leftrightarrow \mathrm{O}=\mathrm{C}<*+3 \mathrm{H}^{*}$ & & -178 & & \\
\hline
\end{tabular}

a $*$ denotes the metal surface.

shown in Figs. 1(a)-1(i). In these figures, we have used the nomenclature $\eta_{i} \mu_{j}$ to designate that $i$-atoms of the adsorbate are bonded to $j$-metal atoms on the surface. The surface species shown in Fig. 1 correspond to propanal hydrogenation. The corresponding surface species for acetone hydrogenation are obtained by replacing the ethyl group and the $\alpha-\mathrm{H}$ atom with methyl groups. Tables I and II show bond lengths for selected surface species. Table III shows calculated total energy changes for acetone $\left(i-\mathrm{C}_{3}\right)$ and propanal $\left(n-\mathrm{C}_{3}\right)$ hydrogenation reactions. The table also shows selected values for acetaldehyde $\left(\mathrm{C}_{2}\right)$ and formaldehyde $\left(\mathrm{C}_{1}\right)$.

Figures 1(a) and 1(b) show adsorption configurations for the $\eta_{1} \mu_{1}$ (perpendicular) and $\eta_{2} \mu_{2}$ (parallel) modes of propanal adsorption. The $\mathrm{C}-\mathrm{O}$ bond in the $\eta_{1}$ mode is tilted from the surface normal. The energy changes for propanal adsorption are -18 and $-7 \mathrm{~kJ} / \mathrm{mol}$ for the $\eta_{1}$ and $\eta_{2}$ modes, respectively, as shown in Table III. The calculated energy change of adsorption is $-19 \mathrm{~kJ} / \mathrm{mol}$ for the $\eta_{1}$ mode of acetone adsorption. Table IV compares the energy changes for molecular adsorption calculated in the present study with the values obtained from previous extended Hückel calculations performed on Pt clusters. ${ }^{19}$ As discussed later, the results from both studies show that the energy change for adsorption in the parallel mode shows a larger variation with carbonyl substituents than does the perpendicular mode of adsorption.

TABLE IV. Comparison of carbonyl molecular adsorptions on $\mathrm{Pt}_{114}$ clusters $^{\mathrm{a}}$ and present work.

\begin{tabular}{lccccc}
\hline \hline & \multicolumn{2}{c}{ Hückel clusters } & & \multicolumn{2}{c}{ DFT (PW91) slabs } \\
\cline { 2 - 3 } \cline { 5 - 6 } $\begin{array}{l}\text { Molecule- } \\
\text { Adsorption mode }\end{array}$ & $\begin{array}{c}\text { Perpendicular } \\
\left(\eta_{1} \mu_{1}\right)\end{array}$ & $\begin{array}{c}\text { Parallel } \\
\left(\eta_{2} \mu_{2}\right)\end{array}$ & & $\begin{array}{c}\text { Perpendicular } \\
\left(\eta_{1} \mu_{1}\right)\end{array}$ & $\begin{array}{c}\text { Parallel } \\
\left(\eta_{2} \mu_{2}\right)\end{array}$ \\
\hline acetone $\left(i-C_{3}\right)$ & -38 & -21 & & -19 & \\
propanal $\left(n-C_{3}\right)$ & & & & -18 & -7 \\
acetaldehyde $\left(C_{2}\right)$ & -39 & -59 & & -18 & -4 \\
formaldehyde $\left(C_{1}\right)$ & -39 & -96 & & -14 & -38 \\
\hline
\end{tabular}

${ }^{\mathrm{a} F}$. Delbecq and P. Sautet, Surf. Sci. 295, 353 (1993).
Figure 2 shows the potential energy diagram for the hydrogenation of propanal and acetone on the $\mathrm{Pt}(111)$ slabs. The reference energy for each pathway consists of a clean surface, gas-phase dihydrogen and the corresponding gasphase carbonyl compound. Initially, dihydrogen is adsorbed on the surface (shown by the arrow). The energy change for dissociative adsorption of dihydrogen is $-84 \mathrm{~kJ} / \mathrm{mol}$. The first minimum consists of the adsorbed $\eta_{1}$ carbonyl species and adsorbed hydrogen atoms at an infinite separation from each other. Adsorption and desorption steps are assumed to be nonactivated.

The first transition state $\mathrm{TS}_{1}$ involves hydrogenation of the adsorbed carbonyl species to form an adsorbed alkoxy species. Activation energies for the formation of alkoxy surface intermediates from the molecularly adsorbed carbonyl species and adsorbed hydrogen were 40 and $61 \mathrm{~kJ} / \mathrm{mol}$ for propanal and acetone, respectively. The transition state is shown in Fig. 1(c), and bond lengths are listed in Tables I and II. The $\mathrm{C}-\mathrm{H}$ bond distance at the transition state is 1.40 $\AA$ for both propanal and acetone. Figure 3 shows a plot of energy versus the constrained $\mathrm{C}-\mathrm{H}$ bond length that defines the reaction coordinate for the first propanal hydrogenation step. The transition state is characterized by the highest energy and the transition from repulsive to attractive forces projected along the $\mathrm{C}-\mathrm{H}$ bond.

The geometry of the adsorbed $n$-propoxy species on $\mathrm{Pt}(111)$ is shown in Fig. 1(d). This configuration corresponds to a $\eta_{1} \mu_{1}$ configuration. Tables I and II list bond lengths for atop modes of adsorption for $n$-propoxy and isopropoxy species. The $\mathrm{C}=\mathrm{O}$ double bond appears to have been partially converted to a single bond, since the bond lengths (1.35 and $1.36 \AA$ ) in the adsorbed alkoxy species lie between typical $\mathrm{C}=\mathrm{O}$ lengths in carbonyl groups $(\sim 1.23 \AA)$ and $\mathrm{C}-\mathrm{O}$ single bond lengths in gas phase alcohols $(\sim 1.44 \AA)$.

The next step in the hydrogenation reaction sequence is the addition of an adsorbed hydrogen atom to the oxygen atom of the alkoxy species. The transition state $\mathrm{TS}_{2}$ for addition of a hydrogen atom to an adsorbed $n$-propoxy species 


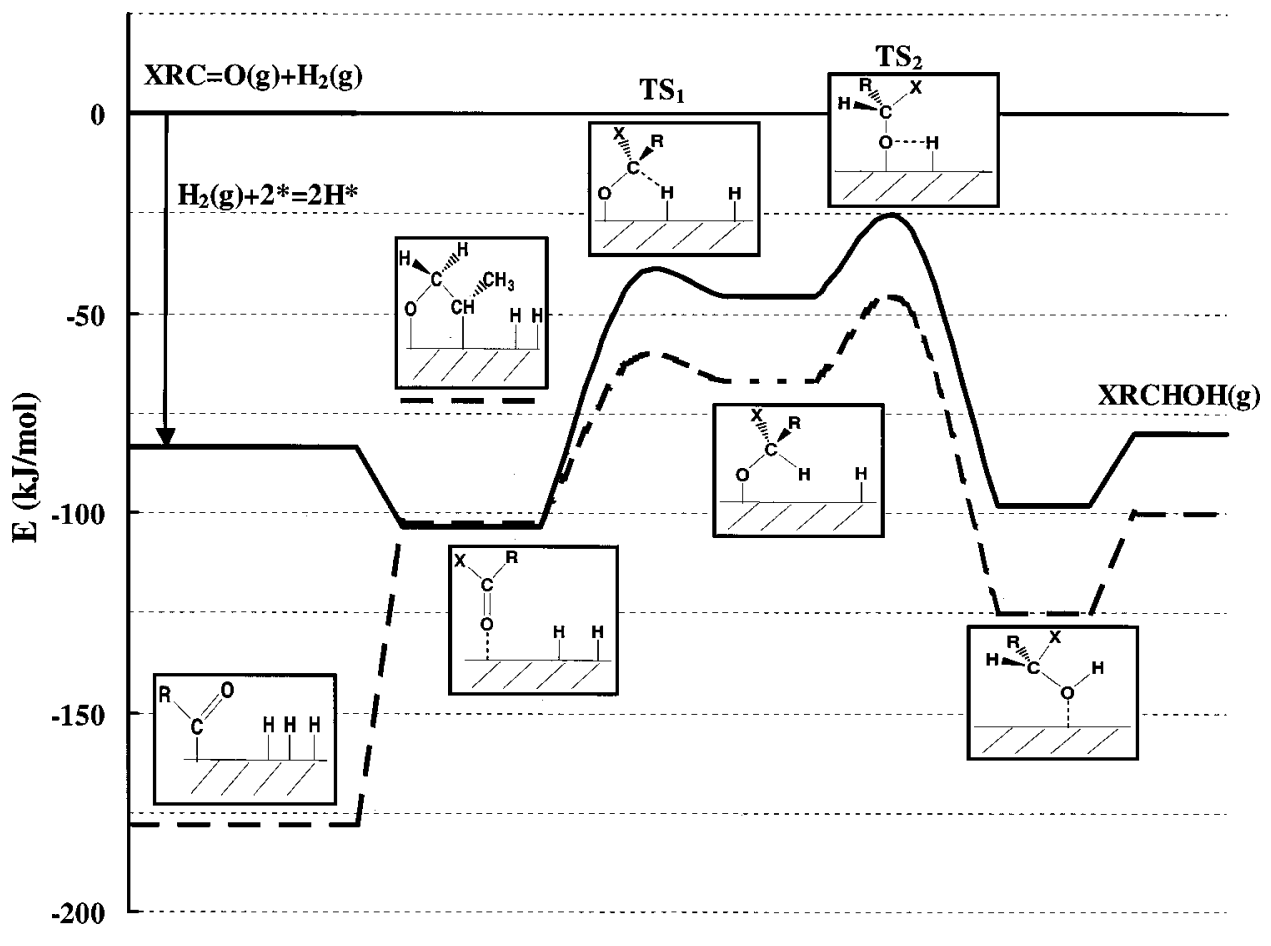

FIG. 2. One-dimensional potentialenergy diagram for carbonyl hydrogenation on $\operatorname{Pt}(111)(\theta=1 / 9 \mathrm{ML})$. Reference is gas-phase carbonyl, dihydrogen, and the clean surface. Note: Excess hydrogens are on the surface unless specified. Transition states are labeled TS. Acetone (solid line): $\mathrm{X}=\mathrm{CH}_{3}$ and $\mathrm{R}=\mathrm{CH}_{3}$; Propanal (dashed line): $\mathrm{X}=\mathrm{H}$ and $\mathrm{R}=\mathrm{CH}_{2} \mathrm{CH}_{3}$.

is shown in Fig. 1(e), and bond lengths are listed in Tables I and II for $n$-propoxy and isopropoxy species, respectively. The activation energies for the formation of adsorbed alcohols from adsorbed alkoxy species and adsorbed hydrogen were about the same for $n$-propoxy and isopropoxy species, $\sim 15 \mathrm{~kJ} / \mathrm{mol}$. The $\mathrm{O}-\mathrm{H}$ distance in the transition state is 1.73 and $1.68 \AA$ for $n$-propoxy and isopropoxy, respectively. Figure 3 shows a plot of energy versus the constrained $\mathrm{O}-\mathrm{H}$

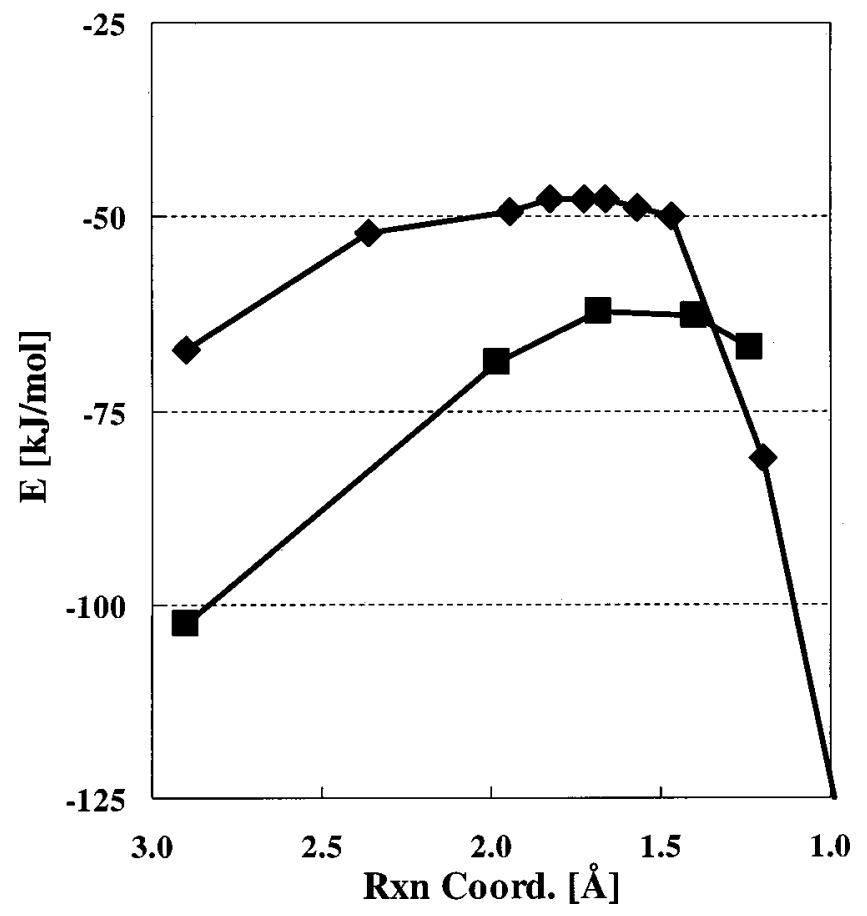

FIG. 3. Plots showing energy vs reaction coordinate for the hydrogenation reactions. ( $\square)$ aldehyde $\leftrightarrow$ alkoxy; $(\diamond)$ alkoxy $\leftrightarrow$ alcohol. bond length representing an approximate reaction coordinate for hydrogenation of the $n$-propoxy species.

Figure 1(f) shows the $\eta_{1} \mu_{1}$ mode of alcohol adsorption on atop sites. The alcohol interacts with the surface through the oxygen atom. As shown in Tables I and II, the O-Pt distance is 2.41 and $2.52 \AA$ for propanol and isopropanol, respectively. The perpendicular distances between oxygen and the surface are 2.44 and $2.30 \AA$ for propanol and isopropanol, respectively. For comparison, the perpendicular distance between oxygen and the surface for methanol adsorption has been calculated to be $2.41 \AA .{ }^{13}$ The energy changes for adsorption of methanol, $n$-propanol and isopropanol are calculated to be $-32,{ }^{13}-25$ and $-18 \mathrm{~kJ} / \mathrm{mol}$, respectively. It can be seen in Fig. 2 that the energy changes for desorption of these alcohols are lower than the activation energy barriers for dehydrogenation of these alcohols to give adsorbed alkoxy species. These results are in agreement with experimental observations that alcohol desorption is favored over dehydrogenation-decomposition on $\mathrm{Pt}(111){ }^{32}$

We note that DFT calculations have recently been conducted for a hydrogenation pathway to form alcohols (methanol) from carbonyls (formaldehyde) via an alternative intermediate (hydroxymethyl). ${ }^{13}$ Hydrogen addition to the $\mathrm{O}$ atom in adsorbed formaldehyde forms hydroxymethyl and further hydrogenation yields methanol. Formation of methoxy species from adsorbed formaldehyde and surface $\mathrm{H}$ is endothermic $(31 \mathrm{~kJ} / \mathrm{mol})$, while formation of hydroxymethyl from adsorbed formaldehyde and surface $\mathrm{H}$ is exothermic (44 kJ/mol). The activation energies for formation of adsorbed methoxy and hydroxymethyl species from adsorbed formaldehyde and surface $\mathrm{H}$ are 59 and $66 \mathrm{~kJ} / \mathrm{mol}$, respectively. Consequently, it appears that kinetic pathways for hydrogenation of formaldehyde to form methoxy and hydroxymethyl species are competitive. However, van Druten 
et al. suggest carbonyl hydrogenation proceeds via the alkoxy species. ${ }^{9}$

A possible difference in the reactivities of adsorbed propanal and acetone species on $\mathrm{Pt}(111)$ is that the carbon atom of the carbonyl group in propanal is attached to a hydrogen atom, whereas this carbon atom in acetone is attached to two methyl groups. Generally, activation barriers for cleavage of $\mathrm{C}-\mathrm{H}$ bonds are lower than activation barriers for cleavage of $\mathrm{C}-\mathrm{C}$ bonds on Pt. ${ }^{33,34}$ Electron energy loss vibrational spectroscopy (EELS) studies of acetaldehyde adsorption on $\operatorname{Pt}(S)-[6(111) X(100)]$ show formation of acetyl surface species at $137 \mathrm{~K}$ while $\mathrm{C}-\mathrm{C}$ bond cleavage reactions occur at higher temperatures. ${ }^{35}$ Similarly, adsorbed propanal can lose a hydrogen atom bonded to the carbonyl, leading to adsorbed propionyl species and adsorbed $\mathrm{H}$ atom. This adsorbed propionyl species is shown in Fig. 1(g). It can be seen in Table III and Fig. 2 that the dehydrogenation of molecularly adsorbed propanal to form an adsorbed propionyl species and a surface hydrogen atom with infinite separation between each other is very favorable, i.e., the reaction is exothermic by $78 \mathrm{~kJ} / \mathrm{mol}$. The $\mathrm{C}-\mathrm{O}$ bond length in the adsorbed propionyl species is characteristic of a $\mathrm{C}=\mathrm{O}$ double bond, as seen in Table I.

The stabilities of oxametallacycle intermediates were also investigated on $\mathrm{Pt}(111)$ slabs. The oxametallacycle intermediates considered are isomers of acetone and propanal, i.e., their overall stoichiometry is $\mathrm{OC}_{3} \mathrm{H}_{6}$. These oxametallacycles can form, for example, from the dehydrogenation of adsorbed alkoxy species. While, several different structures and adsorption geometries for these species on $\mathrm{Pt}(111)$ were calculated, only the most stable adsorption species are reported. The $\mathrm{OCH}_{2} \mathrm{CHCH}_{3}$ oxametallacycle is shown in Fig. 1(h). This species is bonded to the surface through the $\mathrm{O}$ atom and the $\gamma-\mathrm{C}$ atom on atop sites. Bond lengths for this species are given in Table I. This species is $31 \mathrm{~kJ} / \mathrm{mol}$ less stable than adsorbed propanal $\left(\eta_{1} \mu_{1}\right)$. A second oxametallacycle with the structure $\mathrm{OCH}_{2} \mathrm{CH}_{2} \mathrm{CH}_{2}$ was also investigated, and this species bonds to the surface through the $\mathrm{O}$ atom and the $\delta-\mathrm{C}$ atom. This species is shown in Fig. 1(i), and the bond lengths are listed in Table I. This species is 56 $\mathrm{kJ} / \mathrm{mol}$ less stable than adsorbed propanal $\left(\eta_{1} \mu_{1}\right)$. The equivalent oxametallacycle species formed from acetone has the stoichiometry $\mathrm{OCHCH}_{3} \mathrm{CH}_{2}$, and is bonded to the surface through the $\mathrm{O}$ atom and $\gamma-\mathrm{C}$ atom on atop sites. The bond lengths are tabulated in Table II. This species is 54 $\mathrm{kJ} / \mathrm{mol}$ less stable than the adsorbed acetone $\left(\eta_{1} \mu_{1}\right)$.

\section{DISCUSSION}

The DFT calculations of the present study for molecular adsorption of propanal on $\operatorname{Pt}(111)$ show that the $\eta_{1} \mu_{1}$ mode of adsorption (nearly perpendicular to the surface) and the $\eta_{2} \mu_{2}$ mode of adsorption (parallel to the surface) have similar energetics, differing by less than $15 \mathrm{~kJ} / \mathrm{mol}$. In contrast, acetone only adsorbs in the $\eta_{1} \mu_{1}$ mode and the energy of adsorption is similar to propanal $\eta_{1} \mu_{1}$ adsorption. Although the exact values for the energy changes of adsorption determined from DFT calculations do not agree with values from extended Hückel calculations, ${ }^{19}$ both sets of calculations show similar trends. In particular, the energy change for the perpendicular mode of adsorption is nearly independent of the substituents attached to the carbonyl group. In contrast, the energy change for the parallel mode of adsorption depends on the environment of the carbonyl group (formaldehyde $>$ aldehyde). Formaldehyde was the only molecule that favored the parallel mode of adsorption in DFT slab calculations.

The calculated activation energy for hydrogenation of acetone to form isopropoxy species was $\sim 20 \mathrm{~kJ} / \mathrm{mol}$ higher than the corresponding value for hydrogenation of propanal (see Fig. 2). These values would suggest that hydrogenation of acetone should be slower than hydrogenation of propanal. This prediction would be in disagreement with experimental investigations, where the rates of acetone hydrogenation are found to be higher than the rates of propanal hydrogenation over supported Pt catalysts. ${ }^{8,10}$ Although one cannot exclude the effects of structure sensitivity for this reaction, where the hydrogenation rate of the two molecules is reversed on defects-step sites, we examine here the possibility that another factor is responsible for the slower rate of propanal hydrogenation compared to acetone. Based on our calculations, we suggest that the slower rate of propanal hydrogenation is caused by the presence of strongly adsorbed spectator species, such as adsorbed propionyl species, which block sites for hydrogenation reactions.

Van Druten et al. suggested that surface blocking by spectator surface species was more important in the presence of propanal compared to acetone. ${ }^{8}$ For example, they reported that propanal suppressed the hydrogenation of acetone when both of these species were passed over the catalyst in the presence of $\mathrm{H}_{2}$. Therefore, the lower reactivity of propanal compared to acetone, and the suppression of acetone hydrogenation by the presence of propanal point to the formation of a strongly adsorbed spectator species from propanal. ${ }^{8}$ The results from the present DFT slab calculations show that the energy changes are essentially the same for the adsorption of propanal and acetone to form the most stable $\eta_{1}$-adsorbed species. As a result, blocking of surface sites by adsorbed propanal species does not appear to be the origin for the lower reactivity of propanal compared to acetone hydrogenation and the suppression of acetone hydrogenation by the presence of propanal. Furthermore, DFT calculations involving oxametallacycles show that these surface species are less stable than molecularly adsorbed carbonyl species. Consequently, the oxametallacycle species do not inhibit surface reactions.

A significant difference between the chemical structures of propanal and acetone is the presence of an $\alpha-\mathrm{H}$ in propanal. Furthermore, cleavage of the $\mathrm{C}-\mathrm{H}$ bond is facile, ${ }^{36}$ whereas cleaving the corresponding $\mathrm{C}-\mathrm{C}$ bond in acetone is expected to be more difficult. In addition, cleaving bonds adjacent to the carbonyl group should occur more easily for bonding modes that bring the carbon atom of the carbonyl group closer to the surface. As shown in Figs. 1(a) and 1(b), the $\eta_{2}$ (parallel) mode of adsorption for the carbonyl group is closer to the surface. Moreover, acetone does not adsorb in the $\eta_{2}$ (parallel) mode. Based on the above arguments, it appears that adsorbed propanal should be a better candidate 
for dehydrogenation reactions compared to adsorbed acetone.

The results of the present DFT calculations indicate that the decomposition of adsorbed propanal to form adsorbed propionyl species and adsorbed hydrogen on $\mathrm{Pt}(111)$ is a highly exothermic process $(78 \mathrm{~kJ} / \mathrm{mol})$, and these propionyl species could block sites and therefore lead to low hydrogenation rates. It is apparent in Fig. 2 that the formation of adsorbed propionyl species and atomic hydrogen is the most stable minimum on the energy diagram for the conversion of propanal. To test whether the coverage by adsorbed propionyl species could be significant under reaction conditions for propanal hydrogenation, we consider the following quasiequilibrated reaction:

$$
\operatorname{Propanal}(g)+* \leftrightarrow \text { propionyl }^{*}+\frac{1}{2} \mathrm{H}_{2}(g),
$$

where $*$ represents a surface site and propionyl* is the adsorbed propionyl species. According to the DFT calculations of the present study, the energy change for this reaction is $-52 \mathrm{~kJ} / \mathrm{mol}$. The standard entropy change (at a pressure of 1 atm and a temperature of $400 \mathrm{~K}$ ) for this reaction can be estimated to be $-95 \mathrm{~J} /(\mathrm{mol} \mathrm{K})$, if the entropy for adsorbed propionyl species is assumed to be equal to the vibrational and rotational entropy contributions of gaseous propanal (i.e., equal to the standard entropy of gaseous propanal minus the translational entropy contribution for three degrees of translation). The equilibrium constant for this reaction at $400 \mathrm{~K}$ is thus estimated to be $60 \mathrm{~atm}^{-0.5}$. Therefore, the surface coverage by adsorbed propionyl species may well be significant at typical reaction conditions used for studies of propanal hydrogenation.

The dehydrogenation of adsorbed formaldehyde to form adsorbed formyl species and adsorbed $\mathrm{H}$ on $\mathrm{Pt}(111)$ is exothermic $(-60 \mathrm{~kJ} / \mathrm{mol})$ and is comparable to the energy change for reaction of adsorbed formaldehyde with surface $\mathrm{H}$ to form adsorbed hydroxymethyl $(-44 \mathrm{~kJ} / \mathrm{mol}) .{ }^{13}$ Considering the following quasi-equilibrated reaction, we can estimate the relative surface coverages of hydroxymethyl and formyl species:

$$
\text { hydroxymethyl } l^{*} \leftrightarrow \text { formyl }^{*}+\mathrm{H}_{2}(g)
$$

The energy change for this reaction is $+27 \mathrm{~kJ} / \mathrm{mol}$ on $\mathrm{Pt}(111) .{ }^{13}$ The standard entropy change (at a pressure of 1 atm and a temperature of $400 \mathrm{~K}$ ) for this reaction can be estimated to be $+137 \mathrm{~J} /(\mathrm{mol} \mathrm{K})$, if the entropy for adsorbed hydroxymethyl and formyl species are assumed to be equal to the vibrational and rotational entropy contributions of gaseous formaldehyde. The equilibrium constant for this reaction at $400 \mathrm{~K}$ is thus estimated to be $4000 \mathrm{~atm}$. Consequently, surface coverage of adsorbed formyl species will be several orders of magnitude larger than the coverage by hydroxymethyl species. Propionyl and 1-hydroxypropyl are the $\mathrm{C}_{3}$ oxygenate equivalents of formyl and hydroxymethyl. By analogy with the $\mathrm{C}_{1}$ oxygenate results, we suggest that adsorbed propionyl species are most likely spectator species on Pt during propanal hydrogenation.

\section{CONCLUSIONS}

Adsorption of propanal on $\mathrm{Pt}(111)$ takes place preferentially in the $\eta_{1} \mu_{1}$ (perpendicular) binding mode compared to the $\eta_{2} \mu_{2}$ (parallel) binding mode. Acetone only binds in the $\eta_{1} \mu_{1}$ binding mode, and the energy changes for adsorption of these two molecules in the favored $\eta_{1} \mu_{1}$ (perpendicular) binding mode are similar, i.e., equal to $-20 \mathrm{~kJ} / \mathrm{mol}$. The results from the present DFT calculations for the adsorption of formaldehyde, acetaldehyde, propanal, and acetone agree with trends reported in the literature estimated from Hückel calculations. ${ }^{19}$ In particular, the energy change for the perpendicular mode of adsorption is nearly independent of the substituents attached to the carbonyl group, whereas, the energy change for the parallel mode of adsorption depends strongly on the substituents on the carbonyl group (formaldehyde $>$ aldehyde). Formaldehyde was the only molecule that favored the parallel mode of adsorption in DFT slab calculations.

The activation energy barrier for hydrogenation of adsorbed acetone to form adsorbed isopropoxy species was higher compared to the hydrogenation of adsorbed propanal to form $n$-propoxy species (i.e., 60 compared to $40 \mathrm{~kJ} / \mathrm{mol}$ ). The subsequent activation energy barriers for addition of a hydrogen atom to adsorbed alkoxy species to form adsorbed alcohols are approximately equal to $15 \mathrm{~kJ} / \mathrm{mol}$. These results would suggest that the rate of propanal hydrogenation over Pt should be faster compared to acetone hydrogenation, in contrast to experimental results in the literature. ${ }^{8,9}$ This apparent discrepancy appears to be associated with the formation of strongly adsorbed spectator species that block surface sites during propanal hydrogenation.

Oxametallacycles are less stable than molecularly adsorbed carbonyl species, and therefore, may not act as spectator species. However, dehydrogenation of adsorbed propanal by removal of the $\alpha-\mathrm{H}$ atom bonded to the carbon atom of the carbonyl group leads to an adsorbed propionyl species plus adsorbed atomic hydrogen, and this reaction is exothermic by $78 \mathrm{~kJ} / \mathrm{mol}$. This type of $\mathrm{H}$ atom is not present in acetone, and formation of an adsorbed acetyl species in this case would require breaking a $\mathrm{C}-\mathrm{C}$ bond, which is, in general, much more difficult than $\mathrm{C}-\mathrm{H}$ bond breaking.

\section{ACKNOWLEDGMENTS}

The authors thank the National Science Foundation for providing financial support for this work. R.A. acknowledges a Ford Predoctoral Fellowship from the National Research Council. J.G. acknowledges a National Science Foundation Predoctoral Fellowship. Parts of the calculations were performed at NSF-NPACI and DOE-NERSC supercomputing resources. Finally, Randy Cortright is thanked for valuable discussions throughout this work.

\footnotetext{
${ }^{1}$ M. Mavrikakis and M. A. Barteau, J. Mol. Catal. A: Chem. 131, 135 (1998).

${ }^{2}$ T. B. L. W. Marinelli, S. Nabuurs, and V. Ponec, J. Catal. 151, 431 (1995).

${ }^{3}$ P. Beccat, J. C. Bertolini, Y. Gauthier, J. Massardier, and P. Ruiz, J. Catal. 126, 451 (1990).

${ }^{4}$ C. G. Raab and J. A. Lercher, J. Mol. Catal. 75, 71 (1992).

${ }^{5}$ G. Neri, C. Milone, A. Donato, L. Mercadente, and A. M. Visco, J. Chem. Technol. Biotechnol. 60, 83 (1994).
} 
${ }^{6}$ N. Homs, J. Llorca, P. R. de la Piscina, F. Rodriguez-Reinoso, A. Sepulveda-Escribano, and J. Silvestre-Albero, Phys. Chem. Chem. Phys. 3, 1782 (2001)

${ }^{7}$ F. Coloma, J. Llorca, N. Homs, P. R. de la Piscina, F. Rodriguez-Reinoso, and A. Sepulveda-Escribano, Phys. Chem. Chem. Phys. 2, 3063 (2000).

${ }^{8}$ G. M. R. van Druten and V. Ponec, Appl. Catal., A 191, 153 (2000).

${ }^{9}$ G. M. R. van Druten and V. Ponec, Appl. Catal., A 191, 163 (2000).

${ }^{10}$ N. V. Pavlenko, A. I. Tripol'skii, and G. I. Golodets, Kinet. Katal. 30, 1192 (1989).

${ }^{11}$ Z. M. Liu and M. A. Vannice, Surf. Sci. 316, 337 (1994).

${ }^{12}$ C. Panja, N. Saliba, and B. E. Koel, Surf. Sci. 395, 248 (1998).

${ }^{13}$ J. Greeley and M. Mavrikakis, J. Amer. Chem. Soc. (to be published).

${ }^{14}$ K. D. Gibson and L. H. Dubois, Surf. Sci. 233, 59 (1990).

${ }^{15}$ H. Ihm, J. W. Medlin, M. A. Barteau, and J. M. White, Langmuir 17, 798 (2001).

${ }^{16}$ M. Mavrikakis, D. J. Doren, and M. A. Barteau, J. Phys. Chem. B 102, 394 (1998).

${ }^{17}$ J. W. Medlin, M. Mavrikakis, and M. A. Barteau, J. Phys. Chem. B 103, 11169 (1999).

${ }^{18}$ F. Delbecq and P. Sautet, Langmuir 9, 197 (1993).

${ }^{19}$ F. Delbecq and P. Sautet, Surf. Sci. 295, 353 (1993)

${ }^{20}$ B. Hammer, L. B. Hansen, and J. K. Nørskov, Phys. Rev. B 59, 7413 (1999).

${ }^{21}$ D. H. Vanderbilt, Phys. Rev. B 41, 7892 (1990).

${ }^{22}$ J. A. White and D. M. Bird, Phys. Rev. B 50, 4954 (1994).
${ }^{23}$ J. P. Perdew, J. A. Chevary, S. H. Vosko, K. A. Jackson, M. R. Pederson, D. J. Singh, and C. Fiolhais, Phys. Rev. B 46, 6671 (1992).

${ }^{24}$ G. Kresse and J. Furthmuller, Comput. Mater. Sci. 6, 15 (1996).

${ }^{25}$ R. M. Watwe, R. D. Cortright, J. K. Nørskov, and J. A. Dumesic, J. Phys. Chem. B 104, 2299 (2000).

${ }^{26}$ R. P. Elliott, Ph.D., Constitution of Binary Alloys, First Supplement (McGraw-Hill, New York, 1965).

${ }^{27}$ A. Alavi, P. Hu, T. Deutsch, P. L. Silvestrelli, and J. Hutter, Phys. Rev. Lett. 80, 3650 (1998).

${ }^{28}$ R. M. Watwe, H. S. Bengaard, J. R. Rostrup-Nielsen, J. A. Dumesic, and J. K. Nørskov, J. Catal. 189, 16 (2000).

${ }^{29}$ G. Mills, H. Jónsson, and G. K. Schenter, Surf. Sci. 324, 305 (1995).

${ }^{30}$ G. Henkelman, B. Uberuaga, and H. Jónsson, J. Chem. Phys. 13, 9904 (2000).

${ }^{31}$ G. Henkelman and H. Jónsson, J. Chem. Phys. 113, 9978 (2000).

${ }^{32}$ B. A. Sexton, K. D. Rendulic, and A. E. Hughes, Surf. Sci. 121, 181 (1982).

${ }^{33}$ F. Zaera and G. A. Somorjai, J. Phys. Chem. 89, 3211 (1985).

${ }^{34}$ R. D. Cortright, R. M. Watwe, and J. A. Dumesic, J. Mol. Catal. A: Chem. 163, 91 (2000).

${ }^{35}$ R. W. McCabe, C. L. DiMaggio, and R. J. Madix, J. Phys. Chem. 89, 854 (1985).

${ }^{36}$ K. I. Gursahani, R. Alcala, R. D. Cortright, and J. A. Dumesic, Appl. Catal., A 222, 369 (2001). 